Jurnal Mandala Pharmacon Indonesia, Vol 5.No.2 Desember 2019

Avaiable online at www.jurnal-pharmaconmw.com/jmpi

p-ISSN : 2442-6032

$e$-ISSN : 2598-9979

\title{
Formulasi Sediaan Lipstik Ekstrak Kulit Buah Ruruhi (Syzygium policephalum Merr) Sebagai Pewarna
}

\author{
Ulfi Dwicahyani ${ }^{1}$, Muhammad Isrul ${ }^{1}$, Wa Ode Nova Noviyanti ${ }^{2}$ \\ ${ }^{1}$ Program Studi Farmasi STIKES Mandala Waluya Kendari \\ ${ }_{2}^{2}$ Program Studi Kesehatan Masyarakat STIKES Mandala Waluya Kendari
}

\begin{abstract}
ABSTRAK
Kulit buah ruruhi (Syzygium policephalum Merr) memiliki potensi untuk dimanfaatkan sebagai pewarna alami karena memiliki warna yang menarik. Warna merah hingga unggu dari kulit buah ruruhi disebabkan oleh adanya pigmen antosianin yang merupakan turunan senyawa flavanoid.Tujuan dari penelitian ini adalah untuk membuat sediaan lipstik dengan memanfaatkan pewarna alami yang terkandung dalam kulit buah ruruhi. Penelitian dilakukan secara laboratorium eksperimen, sampel diekstraksi dengan metode maserasi menggunakan pelarut etanol $96 \%$ dan asam sitrat $1 \%$ diperoleh ekstrak kental sebanyak 20 gram. Ekstrak kental digunakan sebagai pewarna dalam pembuatan lipstik pada konsentrasi ekstrak 5\%, 10\%, dan $15 \%$. Selanjutnya dilakukan evaluasi fisik sediaan meliputi uji stabilitas, $\mathrm{pH}$, homogenitas, uji iritasi, uji kesukaan (Hedonic test) dan cycling test pada
\end{abstract}

suhu $4^{\circ} \mathrm{C}, 25^{\circ} \mathrm{C}$ dan $43^{\circ} \mathrm{C}$. Hasil penelitian ini menunjukkan bahwa sediaan lipstik ekstrak kulit buah ruruhi yang dibuat berwarna merah muda dan merah tua, memiliki pH 3-4, homogen, tidak mengiritasi, warna menempel ketika dileskan pada konsentrasi estrak $10 \%$ dan $15 \%$ dan stabil pada kondisi penyimpanan suhu ruang $\left(25^{\circ} \mathrm{C}\right)$ namun tidak stabil pada kondisi penyimpanan suhu tinggi $\left(4 \mathrm{O}^{\circ} \mathrm{C}\right)$ dan cycling test.

Keywords: Lipstik, ruruhi (Syzygium policephalum Merr),Antosianin.

\section{Penulis Korespondensi :}

Ulfi Dwicahyani

Program Studi Farmasi STIKES Mandala Waluya Kendari

E-mail : Ulvydwicahyani@gmail.com

\section{PENDAHULUAN}

Kosmetik adalah sediaan yang dimaksudkan untuk digunakan pada bagian luar tubuh manusia (rambut, kuku, bibir dan organ genital bagian luar) atau gigi terutama untuk membersihkan, mengubah penampilan, memperbaiki dan memelihara tubuh pada kondisi baik. Salah satu kosmetik yang paling sering digunakan adalah sediaan lipstick (Adliani,2012).

Lipstik atau pewarna bibir adalah sediaan kosmetika yang digunakan untuk mewarnai bibir agar dapat menyempurnakan bentuk dan warna dekoratif padabibiruntuk menunjang penampilan. Lipstik sangat mungkin untuk tertelan bersama ludah atau makanan dan minuman yang dikonsumsi sehingga dapat berdampak buruk jika terdapat bahan pewarna berbahaya dalam lipstik. Jika pewarna sintetik berbahaya terus tertelan secara berulang pada pemakaian lipstik dapat mengakibatkan keracunan, iritasi dan gangguan pada hati (Lestiana,2014).

Zat warna menurut asalnya terdiri dari zat warna sintetis dan zat warna alami (Winarti, 2008). Pemanfaatan zat warna alami dalam formulasi lipstik merupakan salah satu alternatif untuk masyarakat agar dapat menggunakan lipstik yang mengandung bahan pewarna alami. Zat warna alami merupakan zat warna yang diperoleh dari tumbuhan, hewan, atau sumber mineral. Zat warnaini sejak dahulu telah 
digunakan untuk pewarna makanan dan sampai sekarang penggunaanya secara umum dianggap lebih aman dari pada zat warna sintetis (Adliani,2012).

Salah satu pigmen yang dapat diekstraksi dari sumber bahan alami adalah antosianin yang termasuk golongan senyawa flavonoid yang pada umumnya larut dalam air. Pigmen dalam tanaman memiliki fungsi untuk memberikan warna pada bunga, buah dan daun tumbuhan hijau, dan telah banyak digunakan sebagai pewarna alami pada berbagai produk pangan dan berbagai aplikasi lainnya. Antosianin dapat digunakan sebagai bahan pewarna alami (Risnawati, 2012). Beberapa Penelitian telah membuktikan pengunaan pigmen antosianin sebagai pewarna. Nurany et al., (2018) menggunakan zat warna dari ekstrak bunga rosella sebagai pewarna yang stabil pada sediaan lipstik. Peneltian lain dilakukan oleh Rosita (2015) yang mengunakan ekstrak ubi jalar ungu sebagai pewarna lipstik.

\section{Buah Ruruhi (Syzygium} polycephalum Merr) merupakan buah lokal dari suku jambu-jambuan yang cukup banyak ditemukan di daerah kota Kendari. Menurut Irnawati et al., (2017) kulit dan buah ruruhi memiliki kandungan antosianin yang diduga sebagai pigmen yang membuat kulitnya berwarna merah hingga ungu sehingga memiliki tampilan yang cukup eksotis dan menawan. Selain itu, buah ruruhi memiliki warna yang tahan lama dan tidak mudah hilang sehingga cocok dimanfaatkansebagai pewarna alami.

Berdasarkan perkembangan pewarna alami yang dapat digunakan sebagai zat warna lipstik dan masih sedikitnya pemanfaatan buah ruruhi, maka penulis tertarik untuk melakukan penelitian terhadap buah ruruhi dengan cara memanfaatkan buah ruruhi kemudian diaplikasikan untuk mengembangkan suatu formulasi lipstik dengan ekstrak buah ruruhi sebagai zat warna dan melihat kestabilanya secara fisik.

\section{METODE PENELITIAN}

\section{Alat}

Alat yang digunakan pada penelitian ini yaitu, batang pengaduk, blender (miyako), beaker glass (pyrex), cawan porselen, cetakan lipstik, wadah lipstik, gegep besi, hotplate, kain flanel, kaca arloji, pipet tetes, alu/stamper, rotary evaporator ( $R-300 \mathrm{BUCHI}$ ), hair dryer (philips), sendok tanduk, $\mathrm{pH}$ universal, timbangan analitik (Fujitsu), oven (memmert), dan wadah maserasi.

\section{Bahan}

Bahan-bahan yang digunakan padapenelitian yaitu, etanol 96\%, asam sitrat 1\%, ektrak kulit buah ruruhi, aquadest,minyak jarak, cera alba, lanolin, nipagin, nipasol, propilenglikol, tween 80, a- tokoferol, vaselin alba, oleum rosae, setyl alkohol dan cetaceum.

\section{Determinasi Sampel}

Determinasi sampel buah ruruhi (Syzygium polycephalum Merr) dilakukan di laboratorium Biologi, Fakultas Keguruan dan Ilmu Pendidikan Universitas Halu Oleo Kendari. No 74/BIO/PL/VIII/2019

\section{Penyiapan Sampel Penelitian}

Sampel yang digunakan adalah kulit buah ruruhi. Buah ruruhi yang telah dipetik disortasi basah dengan tujuan untuk menghilangkan kotoran yang melekat pada buah dengan menggunakan air yang mengalir. Setelah itu buah ruruhi dikupas diambil bagian kulit buah lalu ditiriskan dengan cara diangin-anginkan untuk mengurangi kandungan airnya, kemudian ditimbang sebanyak 250 .

\section{Ekstraksi sampel}

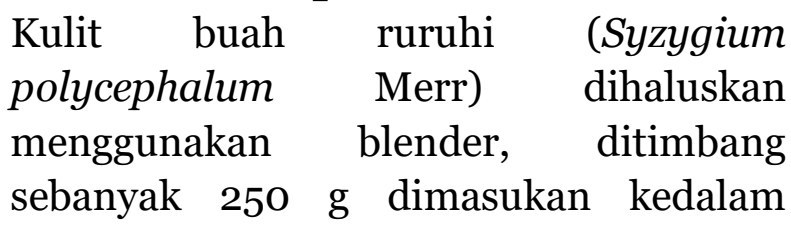


wadah maserasi. Kemudian ditambahkan alkohol 96\% sebanyak $1250 \mathrm{~mL}$ yang dicampur dengan asam sitrat 1\% hingga sampel terendam atau selapis di atas permukaan sampel. Ditutup toples dengan lakban hitam, kemudian dilakukan ekstraksi secara maserasi selama 24 jam pada suhu kamar, terlindung dari cahaya sambil sesekali diaduk. Dilakukan penyarian setelah 24 jam, disaring menggunakan kain flanel, selanjutnya filtrat yang diperoleh dipekatkan dengan rotary evaporator (rotavapor) pada temperatur $\pm 40^{\circ} \mathrm{C}-$ $50^{\circ} \mathrm{C}$ hingga menghasilkan ekstrak kental.

\section{Pembuatan Sediaan Lipstik Ekstrak Kulit Buah Ruruhi}

Tabel 1. Formula Sediaan Lipstik Ekstrak kulit buah ruruhi (Syzygium polycephalum Merr). Setiap $3 \mathrm{~g}$ sediaan mengandung :

\begin{tabular}{|c|c|c|c|c|c|}
\hline \multirow{2}{*}{ Komposisi } & \multicolumn{5}{|c|}{ Sediaan (\%) } \\
\hline & $\mathrm{F} 1$ & $\mathrm{~F} 2$ & F3 & $\mathrm{F}_{4}$ & Fungsi \\
\hline $\begin{array}{l}\text { Ekstrak kulit } \\
\text { buah ruruhi }\end{array}$ & o & 5 & 10 & 15 & Pewarna \\
\hline Minyak jarak & 20 & 20 & 20 & 20 & $\begin{array}{l}\text { Pendispersi } \\
\text { warna, basis } \\
\text { minyak }\end{array}$ \\
\hline Setil Alkohol & 5 & 5 & 5 & 5 & $\begin{array}{l}\text { Pengkilap, } \\
\text { pelembut }\end{array}$ \\
\hline Adeps lanae & 5 & 5 & 5 & 5 & $\begin{array}{c}\text { Basis lemak, } \\
\text { pelembut }\end{array}$ \\
\hline Cera Alba & 20 & 20 & 20 & 20 & $\begin{array}{l}\text { Basis lilin, agen } \\
\text { pemberi } \\
\text { struktur batang }\end{array}$ \\
\hline Propilenglikol & 5 & 5 & 5 & 5 & Humektan \\
\hline Tween 80 & 1 & 1 & 1 & 1 & Emulgator \\
\hline Nipagin & 0,1 & 0,1 & 0,1 & 0,1 & Pengawet \\
\hline Nipasol & 0,02 & 0,02 & 0,02 & 0,02 & Pengawet \\
\hline a-tokoferol & 0,05 & 0,05 & 0,05 & 0,05 & Antioksidan \\
\hline Cetaceum & 10 & 10 & 10 & 10 & Pengisi \\
\hline Oleum rosae & q.s & q.s & q.s & q.s & Pengaroma \\
\hline Vaselin album & 15 & 15 & 15 & 15 & Basis lilin \\
\hline
\end{tabular}

Dalam pembuatan lipstik yang dilakukan dengan membuat 2 massa. Massa 1 merupakan campuran nipagin, propilenglikol dan tween 80 dilarutan dalam cawan, tambahkan ekstrak kulit buah ruruhi hingga bercampur, kemudianitambahkan minyak jarak sedikit demi sedikit sambil diaduk menggunakan stamper hingga bercampur homogen. Massa 2 merupakan hasil penimbangan cera alba, adeps lanae,vaselin alba, nipasol, setil alcohol 
dan cetaceum yang dimasukan kedalam cawan penguap, dileburkan diatas penanggas air. Massa 2 dicampurkan kedalam massa 1 digerus perlahan-lahan hingga homogen, ditambahkan atokoferol sedikit-sedikit dan 2-3 tetes oleum rosae. Tuangkan kedalam wadah (roll up) lipstik didinginkan hingga mengeras sempurna (beku) (Nurany, 2018).

\section{Evaluasi Sediaan \\ Uji stabilitas}

Pengujian stabilitas sediaan dievaluasi untuk melihat perubahan bentuk, warna dan bau dari sediaan lipstik berdasarkan waktu penyimpanan pada suhu kamar. Evaluasi dilakukan setiap minggu hingga hari ke-30. Perubahan bentuk, warna, bau mengacu kepada ada tidaknya perubahan bentuk, warna, dan bau dari sediaan lipstik dari sesuai dengan hasil awal pencetakan (Risnawatiet al., 2012).

\section{Uji PH}

Sampel dibuat dalam konsentrasi 1\% yaitu 1 gram sampel dilarutkan dalam 10 $\mathrm{ml}$ aquades, dicelupkan kertas $\mathrm{pH}$ universal kedalam larutan tersebut. Diamati perubahan warna pada kertas $\mathrm{pH}$ universal. Disesuaikan perubahan warna pada kertas $\mathrm{pH}$ tersebut dengan warna indikator yang tertera pada wadah kertas $\mathrm{pH}$. Penentuan $\mathrm{pH}$ dilakukan tiga kali terhadap masing-masing konsentrasi sediaan lipstik (Risnawati et al., 2012).

\section{Uji Homogenitas}

Pengujian homogenitas lipstik dilakukan dengan cara mengoleskan sediaan lipstik pada bahan yang permukaannya licin dan putih. Pemeriksaan homogenitas dan kestabilan zat warna dari formula lipstik dapat dilakukan dengan cara memotong lipstik secara membujur dan diamati terdapat bintik-bintik pewarna atau tidak berbintik (Risnawati et al., 2012)

\section{Cycling test}

Pada pengujian ini dilakaukan pada suhu dan atau kelembaban pada interval waktu tertentu, yaitu dilakukan selama enam siklus pada tiga suhu yang berbeda yaitu suhu dingin $\left(4^{\circ} \mathrm{C}\right)$, suhu ruang $\left( \pm 25^{\circ} \mathrm{C}\right)$ dan suhu tinggi $\left(43^{\circ} \mathrm{C}\right)$. Satu siklus sebanding dengan 24 jam (Maulina, 2011).

\section{Uji iritasi}

Pemeriksaan ini bertujuan untuk menguji efek iritasi dari lipstik. Pemeriksaan dilakukan dengan metode uji tempel terbuka (Patch Test) pada lengan bawah bagian dalam terhadap 15 orang panelis. Uji tempel terbuka dilakukan dengan mengoleskan sediaan yang dibuat pada lokasi lekatan, dibiarkan terbuka dan diamati apa yang terjadi. Diamati reaksi yang terjadi, reaksi iritasi positif ditandai oleh adanya kemerahan, gatal-gatal, atau bengkak (Risnawati et al., 2012).

\section{Uji Kesukaan (Hedonic Test)}

Uji kesukaan dilakukan secara visual terhadap 15 orang panelis. Setiap panelis diminta untuk mengoleskan formula sediaan yang dibuat pada bibir panelis. Kemudian, panelis memilih variasi formula mana yang paling disukai dari sediaan lipstik yang dianggap menarik, cukup menarik dan tidak menarik dengan cara mengisi kuisioner. Dihitung persentase kesukaan terhadap masingmasing sediaan. (Yuliana, 2014)

\section{HASIL DAN PEMBAHASAN}

\section{Hasil}

Tabel 1. Hasil Pemeriksaan Uji Stabilitas Sediaan Lipstik Ekstrak Kulit Buah Ruruhi

\begin{tabular}{|c|c|c|c|c|c|}
\hline \multirow{2}{*}{ Sediaan } & \multirow{2}{*}{ Pemeriksaan } & \multicolumn{4}{|c|}{ Pengamatan Minggu Ke- } \\
\hline & & I & II & III & IV \\
\hline F1 & \multirow{3}{*}{ Warna } & Putih & Putih & Putih & Putih \\
\hline F2 & & Merah muda & Merah muda & Merah muda & Merah muda \\
\hline $\mathrm{F}_{3}$ & & Merah tua & Merah tua & Merah tua & Merah tua \\
\hline
\end{tabular}




\begin{tabular}{|c|c|c|c|c|c|}
\hline $\mathrm{F} 4$ & & Merah tua & Merah tua & Merah tua & Merah tua \\
\hline $\mathrm{F} 1$ & \multirow{4}{*}{ Bau/ Aroma } & $\begin{array}{c}\text { Bau khas } \\
\text { oleum rosae }\end{array}$ & $\begin{array}{c}\text { Bau khas } \\
\text { oleum rosae }\end{array}$ & $\begin{array}{c}\text { Bau khas } \\
\text { oleum rosae }\end{array}$ & $\begin{array}{c}\text { Bau khas } \\
\text { oleum rosae }\end{array}$ \\
\hline $\mathrm{F} 2$ & & $\begin{array}{c}\text { Bau khas } \\
\text { oleum rosae }\end{array}$ & $\begin{array}{c}\text { Bau khas } \\
\text { oleum rosae }\end{array}$ & $\begin{array}{c}\text { Bau khas } \\
\text { oleum rosae }\end{array}$ & $\begin{array}{c}\text { Bau khas } \\
\text { oleum rosae }\end{array}$ \\
\hline F3 & & $\begin{array}{c}\text { Bau khas } \\
\text { oleum rosae }\end{array}$ & $\begin{array}{c}\text { Bau khas } \\
\text { oleum rosae }\end{array}$ & $\begin{array}{c}\text { Bau khas } \\
\text { oleum rosae }\end{array}$ & $\begin{array}{c}\text { Bau khas } \\
\text { oleum rosae }\end{array}$ \\
\hline $\mathrm{F} 4$ & & $\begin{array}{c}\text { Bau khas } \\
\text { oleum rosae }\end{array}$ & $\begin{array}{l}\text { Bau khas } \\
\text { oleum rosae }\end{array}$ & $\begin{array}{l}\text { Bau khas } \\
\text { oleum rosae }\end{array}$ & $\begin{array}{c}\text { Bau khas } \\
\text { oleum rosae }\end{array}$ \\
\hline $\mathrm{F} 1$ & \multirow{4}{*}{ Bentuk } & Setengah padat & $\begin{array}{l}\text { Setengah } \\
\text { padat }\end{array}$ & Setengah padat & $\begin{array}{c}\text { Setengah } \\
\text { padat }\end{array}$ \\
\hline $\mathrm{F} 2$ & & Setengah padat & $\begin{array}{c}\text { Setengah } \\
\text { padat }\end{array}$ & Setengah padat & $\begin{array}{c}\text { Setengah } \\
\text { padat }\end{array}$ \\
\hline F3 & & Setengah padat & $\begin{array}{c}\text { Setengah } \\
\text { padat }\end{array}$ & Setengah padat & $\begin{array}{c}\text { Setengah } \\
\text { padat }\end{array}$ \\
\hline $\mathrm{F} 4$ & & Setengah padat & $\begin{array}{c}\text { Setengah } \\
\text { padat }\end{array}$ & Setengah padat & $\begin{array}{c}\text { Setengah } \\
\text { padat }\end{array}$ \\
\hline
\end{tabular}

\section{Keterangan :}

F1 : Lipstik tanpa ekstrak kulit buah ruruhi

F2 : Lipstik dengan konsentrasiekstrak kulit buah ruruhi $5 \%$

F3 : Lipstik dengan konsentrasi ekstrak kulit buah ruruhi10\%

F4 : Lipstik dengan konsentrasi ekstrak kulit buah ruruhi15\%

Tabel 2. Hasil Pemeriksaan Uji pH Sediaan Lipstik Ekstrak Kulit Buah Ruruhi

\begin{tabular}{ccccc}
\hline \multirow{2}{*}{ Sediaan } & \multicolumn{5}{c}{ Pengamatan Minggu Ke- } \\
\cline { 2 - 5 } & I & II & III & IV \\
\hline F1 & 7 & 7 & 7 & 7 \\
\hline F2 & 4 & 4 & 4 & 4 \\
\hline F3 & 3 & 3 & 3 & 3 \\
\hline F4 & 3 & 3 & 3 & 3 \\
\hline
\end{tabular}

Keterangan :

F1 $\quad$ : Lipstik tanpa ekstrak kulit buah ruruhi

F2 : Lipstik dengan konsentrasi ekstrak kulit buah ruruhi $5 \%$

F3 : Lipstik dengan konsentrasi ekstrak kulit buah ruruhi 10\%

F4 : Lipstik dengan konsentrasi ekstrak kulit buah ruruhi 15\%

Tabel 3. Hasil PemeriksaanUjiHomogenitas Sediaan Lipstik Ekstrak Kulit Buah Ruruhi

\begin{tabular}{ccccc}
\multirow{2}{*}{ Sediaan } & \multicolumn{4}{c}{ Pengamatan Minggu Ke- } \\
\cline { 2 - 5 } & I & II & III & IV \\
\hline F1 & Homogen & Homogen & Homogen & Homogen \\
\hline F2 & Homogen & Homogen & Homogen & Homogen \\
\hline F3 & Homogen & Homogen & Homogen & Homogen \\
\hline F4 & Homogen & Homogen & Homogen & Homogen
\end{tabular}

\section{Keterangan :}

F1 : Lipstik tanpa ekstrak kulit buah ruruhi

F2 : Lipstik dengan konsentrasi ekstrak kulit buah ruruhi 5\%

F3 : Lipstik dengan konsentrasi ekstrak kulit buah ruruhi 10\%

F4 : Lipstik dengan konsentrasi ekstrak kulit buah ruruhi 15\% 
Tabel 4. Hasil Pemeriksaan Uji iritasi Sediaan Lipstik Ekstrak Kulit Buah Ruruhi

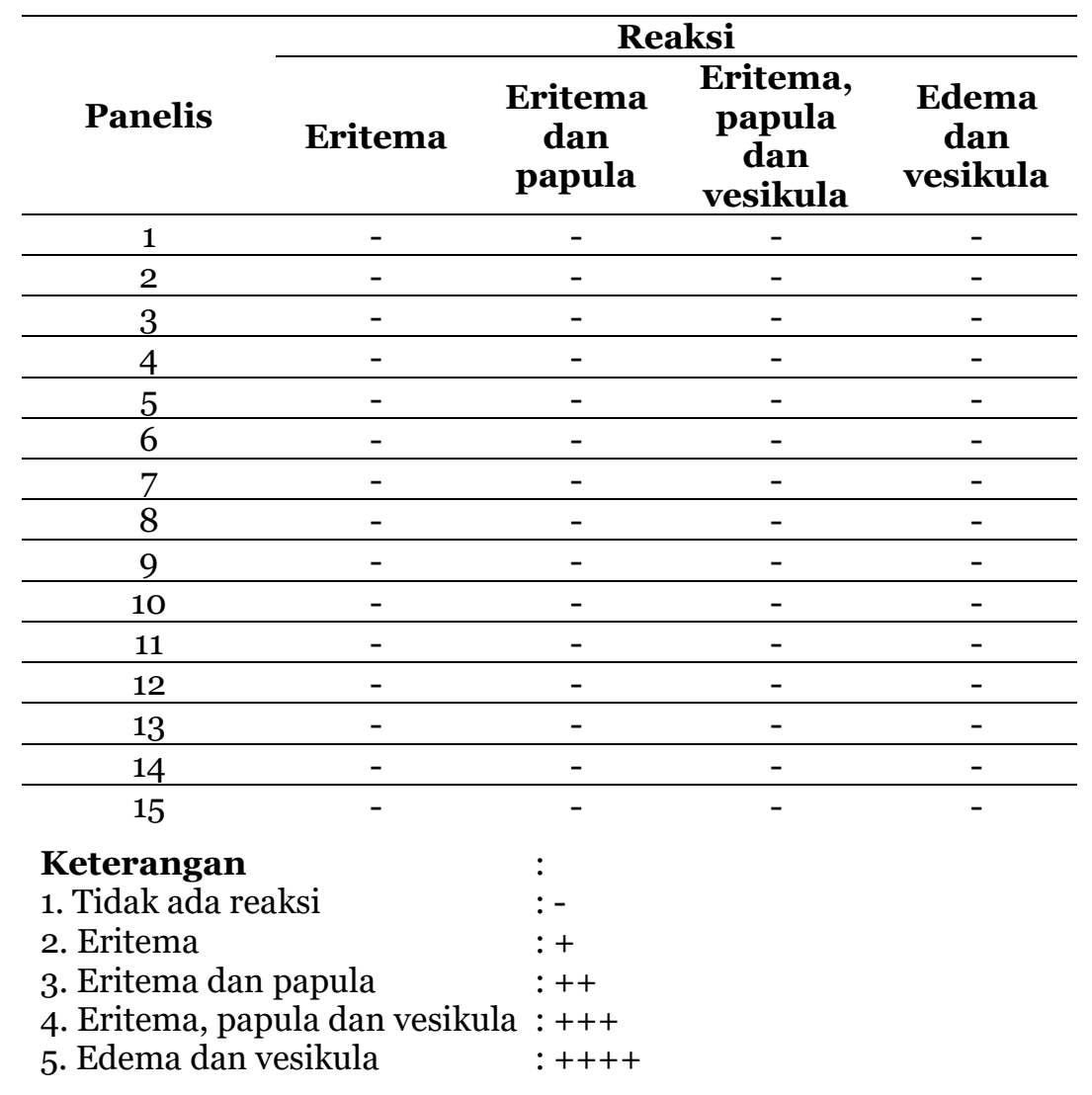

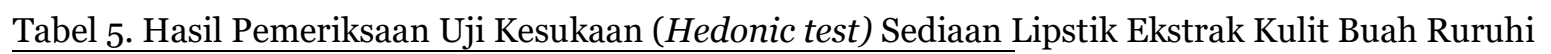

\begin{tabular}{cccc}
\hline \multirow{2}{*}{ Sediaan } & \multicolumn{3}{c}{ Penilaian } \\
\cline { 2 - 4 } & $\begin{array}{c}\text { Sangat } \\
\text { menarik }\end{array}$ & $\begin{array}{c}\text { Cukup } \\
\text { menarik }\end{array}$ & $\begin{array}{c}\text { Tidak } \\
\text { menarik }\end{array}$ \\
\hline F1 & $13,33 \%$ & $13,33 \%$ & $73,33 \%$ \\
\hline F2 & $26,67 \%$ & $33,33 \%$ & $40 \%$ \\
\hline F3 & $40 \%$ & $40 \%$ & $20 \%$ \\
\hline F4 & $66,67 \%$ & $26,67 \%$ & $6,67 \%$ \\
\hline
\end{tabular}

\section{Keterangan :}

F1 : Lipstik tanpa ekstrak kulit buah ruruhi

F2 : Lipstik dengan konsentrasi ekstrak kulit buah ruruhi $5 \%$

F3 : Lipstik dengan konsentrasi ekstrak kulit buah ruruhi 10\%

F4 : Lipstik dengan konsentrasi ekstrak kulit buah ruruhi 15\%

Tabel 6.Hasil Pemeriksaan Uji Stabilitas Sediaan Lipstik pada Cycling Test

\begin{tabular}{|c|c|c|c|c|c|}
\hline \multirow{2}{*}{ Sediaan } & \multirow{2}{*}{ Pemeriksaan } & \multicolumn{4}{|c|}{ Pengamatan Minggu Ke- } \\
\hline & & I & II & III & IV \\
\hline $\mathrm{F} 1$ & \multirow{4}{*}{ Warna } & Putih & Putih & Putih & Putih \\
\hline F2 & & $\begin{array}{l}\text { Merah } \\
\text { muda }\end{array}$ & $\begin{array}{l}\text { Merah } \\
\text { muda }\end{array}$ & $\begin{array}{l}\text { Merah } \\
\text { muda }\end{array}$ & $\begin{array}{l}\text { Merah } \\
\text { muda }\end{array}$ \\
\hline F3 & & $\begin{array}{c}\text { Merah } \\
\text { tua }\end{array}$ & $\begin{array}{l}\text { Merah } \\
\text { tua }\end{array}$ & $\begin{array}{l}\text { Merah } \\
\text { tua }\end{array}$ & $\begin{array}{l}\text { Merah } \\
\text { tua }\end{array}$ \\
\hline $\mathrm{F} 4$ & & $\begin{array}{c}\text { Merah } \\
\text { tua }\end{array}$ & $\begin{array}{c}\text { Merah } \\
\text { tua }\end{array}$ & $\begin{array}{l}\text { Merah } \\
\text { tua }\end{array}$ & $\begin{array}{l}\text { Merah } \\
\text { tua }\end{array}$ \\
\hline $\mathrm{F} 1$ & \multirow{2}{*}{ Bau/ Aroma } & $\begin{array}{l}\text { Bau khas } \\
\text { oleum } \\
\text { rosae }\end{array}$ & $\begin{array}{c}\text { Bau khas } \\
\text { oleum } \\
\text { rosae }\end{array}$ & $\begin{array}{c}\text { Bau khas } \\
\text { oleum } \\
\text { rosae }\end{array}$ & $\begin{array}{c}\text { Bau khas } \\
\text { oleum } \\
\text { rosae }\end{array}$ \\
\hline $\mathrm{F} 2$ & & $\begin{array}{l}\text { Bau khas } \\
\text { oleum } \\
\text { rosae }\end{array}$ & $\begin{array}{l}\text { Bau khas } \\
\text { oleum } \\
\text { rosae }\end{array}$ & $\begin{array}{l}\text { Bau khas } \\
\text { oleum } \\
\text { rosae }\end{array}$ & $\begin{array}{l}\text { Bau khas } \\
\text { oleum } \\
\text { rosae }\end{array}$ \\
\hline
\end{tabular}




\begin{tabular}{|c|c|c|c|c|c|}
\hline F3 & & $\begin{array}{l}\text { Bau khas } \\
\text { oleum } \\
\text { rosae }\end{array}$ & $\begin{array}{l}\text { Bau khas } \\
\text { oleum } \\
\text { rosae }\end{array}$ & $\begin{array}{l}\text { Bau khas } \\
\text { oleum } \\
\text { rosae }\end{array}$ & $\begin{array}{l}\text { Bau khas } \\
\text { oleum } \\
\text { rosae }\end{array}$ \\
\hline $\mathrm{F} 4$ & & $\begin{array}{c}\text { Bau khas } \\
\text { oleum } \\
\text { rosae }\end{array}$ & $\begin{array}{l}\text { Bau khas } \\
\text { oleum } \\
\text { rosae }\end{array}$ & $\begin{array}{l}\text { Bau khas } \\
\text { oleum } \\
\text { rosae }\end{array}$ & $\begin{array}{l}\text { Bau khas } \\
\text { oleum } \\
\text { rosae }\end{array}$ \\
\hline $\mathrm{F}_{1}$ & \multirow{4}{*}{ Bentuk } & $\begin{array}{l}\text { Setengah } \\
\text { padat }\end{array}$ & $\begin{array}{l}\text { Setengah } \\
\text { padat }\end{array}$ & $\begin{array}{l}\text { Setengah } \\
\text { padat }\end{array}$ & $\begin{array}{l}\text { Setengah } \\
\text { padat }\end{array}$ \\
\hline F2 & & $\begin{array}{l}\text { Setengah } \\
\text { padat }\end{array}$ & $\begin{array}{l}\text { Setengah } \\
\text { padat }\end{array}$ & $\begin{array}{l}\text { Setengah } \\
\text { padat }\end{array}$ & $\begin{array}{l}\text { Setengah } \\
\text { padat }\end{array}$ \\
\hline$F_{3}$ & & $\begin{array}{c}\text { Setengah } \\
\text { padat }\end{array}$ & $\begin{array}{l}\text { Setengah } \\
\text { padat }\end{array}$ & $\begin{array}{l}\text { Setengah } \\
\text { padat }\end{array}$ & $\begin{array}{c}\text { Setengah } \\
\text { padat }\end{array}$ \\
\hline $\mathrm{F}_{4}$ & & $\begin{array}{c}\text { Setengah } \\
\text { padat }\end{array}$ & $\begin{array}{l}\text { Setengah } \\
\text { padat }\end{array}$ & $\begin{array}{l}\text { Setengah } \\
\text { padat }\end{array}$ & $\begin{array}{c}\text { Setengah } \\
\text { padat }\end{array}$ \\
\hline
\end{tabular}

\section{Keterangan :}

F1 : Lipstik tanpa ekstrak kulit buah ruruhi

F2 : Lipstik dengan konsentrasi ekstrak kulit buah ruruhi 5\%

F3 : Lipstik dengan konsentrasi ekstrak kulit buah ruruhi 10\%

F4 : Lipstik dengan konsentrasi ekstrak kulit buah ruruhi 15\%

Tabel 7. Hasil Pemeriksaan Uji pH Sediaan Lipstik pada Cycling Test

\begin{tabular}{ccccc}
\hline \multirow{2}{*}{ Sediaan } & \multicolumn{5}{c}{ Pengamatan Minggu Ke- } \\
\cline { 2 - 5 } & I & II & III & IV \\
\hline F1 & 7 & 7 & 7 & 7 \\
\hline F2 & 4 & 4 & 4 & 4 \\
\hline F3 & 3 & 3 & 4 & 4 \\
\hline F4 & 3 & 3 & 4 & 4 \\
\hline
\end{tabular}

Keterangan :

F1 : Lipstik tanpa ekstrak kulit buah ruruhi

F2 : Lipstik dengan konsentrasi ekstrak kulit buah ruruhi 5\%

F3 : Lipstik dengan konsentrasi ekstrak kulit buah ruruhi 10\%

F4 : Lipstik dengan konsentrasi ekstrak kulit buah ruruhi 15\%

Tabel 8.Hasil Pemeriksaan Uji Homogenitas Sediaan Lipstik pada Cycling Test

\begin{tabular}{cllll}
\multirow{2}{*}{ Sediaan } & \multicolumn{4}{c}{ Pengamatan Minggu Ke- } \\
\cline { 2 - 5 } & \multicolumn{1}{c}{ I } & II & III & IV \\
\hline F1 & Homogen & Homogen & Homogen & Homogen \\
\hline F2 & Homogen & Homogen & Homogen & Homogen \\
\hline F3 & Homogen & Homogen & Homogen & Homogen \\
\hline F4 & Homogen & Homogen & Homogen & Homogen \\
\hline
\end{tabular}

\section{Keterangan :}

F1 : Lipstik tanpa ekstrak kulit buah ruruhi

F2 : Lipstik dengan konsentrasi ekstrak kulit buah ruruhi 5\%

F3 : Lipstik dengan konsentrasi ekstrak kulit buah ruruhi 10\%

F4 : Lipstik dengan konsentrasi ekstrak kulit buah ruruhi 15\% 
Tabel 9. Hasil Pemeriksaan Uji iritasi Sediaan Lipstik pada Cycling Test

\begin{tabular}{ccccc}
\hline Panelis & Eritema & $\begin{array}{c}\text { Eritema } \\
\text { dan } \\
\text { papula }\end{array}$ & $\begin{array}{c}\text { Eritema, } \\
\text { papula } \\
\text { dan } \\
\text { vesikula }\end{array}$ & $\begin{array}{c}\text { Edema } \\
\text { dan } \\
\text { vesikula }\end{array}$ \\
\hline 1 & - & - & - & - \\
\hline 2 & - & - & - & - \\
\hline 3 & - & - & - & - \\
\hline 4 & - & - & - & - \\
\hline 5 & - & - & - & - \\
\hline 6 & - & - & - & - \\
\hline 7 & - & - & - & - \\
\hline 8 & - & - & - & - \\
\hline 9 & - & - & - & - \\
\hline 10 & - & - & - & - \\
\hline 11 & - & - & - & - \\
\hline 12 & - & - & - & - \\
\hline 13 & - & - & - & - \\
\hline 14 & - & - & - & - \\
\hline 15 & - & - & - & - \\
\hline
\end{tabular}

Keterangan:

1. Tidak ada reaksi

2. Eritema

3. Eritema dan papula

$:-$

4. Eritema, papula dan vesikula $:+++$

5. Edema dan vesikula

$:++++$

\section{Pembahasan}

Lipstik atau pewarna bibir merupakan sediaan kosmetika yang bertujuan mewarnai bibir agar dapat menunjang penampilan. Zat pewarna dari lipstik dapat berasal dari zat warna sintetis dan zat warna alami. Pemanfaatan zat warna alami dalam formulasi lipstik merupakan salah satu alternatif untuk masyarakat agar dapat menggunakan lipstik yang mengandung bahan pewarna alami. Kulit buah ruruhi (Syzygium polycephalum Merr) merupakan buah berwarna merah hingga ungu yang menarik dan memiliki tampilan yang cukup eksotis dengan warna yang tahan lama. Menurut Irnawati et al., (2017) kulit buah ruruhi memiliki kandungan antosianin total sebesar 5,69 g/Lyang dapat dimanfaatkan sebagai bahan pewarna alami dalam sediaan lipstik.

Determinasi tanaman ruruhi dilakukan di Laboratorium Biologi Fakultas Keguruan dan Ilmu
Pengetahuan Pendidikan Universitas Halu Oleo Kendari, menunjukan bahwa tanaman yang digunakan dalam penelitian ini adalah buah ruruhi (Syzygium polycephalumMerr)suku myrtaceae.

Proses maserasi dilakukan dengan menimbang 250 gram sampel kemudian dilakukan perendaman dengan pelarut etanol $96 \%$ sebanyak $1250 \mathrm{~mL}$ yang telah dicampur dngan asam sitrat $1 \%$. Penambahan asam sitrat untuk memberikan suasana asam dalam pelarut saat proses maserasi. Penambahan asam sitrat dalam etanol berfungsi untuk mendenaturasi membran sel tanaman yang kemudian melarutkan pigmen antosianin sehingga dapat keluar dari sel. Karena, antosianin merupakan senyawa yang tidak stabil di dalam larutan netral atau basa, sehingga ekstraksi dilakukan pada kondisi asam

Proses maserasi berlangsung selama 24 jam dengan sesekali pengadukan, dilanjutkan dengan 
penyaringan agar filtrat dapat dipisahkan dari residunya. Filtrat yang diperoleh lalu dipekatkan dengan rotaryevaporator, hal ini bertujuan agar dapat memekatkan ekstrak serta dapat memisahkan antara pelarut etanol 96\% dengan senyawa aktif dalam kulit buah ruruhi.Proses evaporasi dihentikan apabila pelarut tidak menetes lagi pada labu alas bulat.Dari proses ekstraksi dihasilkan ekstrak pekat berwarna merah tua. Ekstrak kental yang diperoleh dihitung berdasarkan perbandingan berat ekstrak yang dihasilkan dengan berat awal lalu dikalikan 100\%.

Metode ekstraksi yang dipilih menggunakan maserasi karena metode ini cukup mudah dan menggunakan alatalat yang sederhana. Pelarut etanol digunakan karena antosianin dapat larut dengan baik pada pelarut ini. Etanol bersifat lebih selektif, kapang sulit tumbuh dalam etanol 20\% keatas, tidak beracun, netral, absorbsinya baik, dapat bercampur dengan air dalam segala perbandingan dan memerlukan panas yang lebih sedikit untuk proses pemekatan.

Hasil ekstrak kental yang diperoleh digunakan untuk membuat formulasi lipstik dengan konsentrasi 5\%, 10\% dan 15\%.Konsetrasi diperoleh dari studi PreFormulasi yang telah dilakukan sebelumnya.

Lipstik yang telah dibuat dilakukan evaluasi fisik. Evaluasi karakteristik fisik sediaan lipstik ekstrak buah ruruhi dilakukan dengan tujuan untuk mendapatkan sediaan yang menenuhi karakteristik fisik yang sesuai dengan spesifikasi yang telah ditentukan meliputi pengamatan stabilitas, pengukuran $\mathrm{pH}$, pengujian homogenitas, pengujian iritasi, pengujian kesukaan (Hedonic test) dan pengujian cycling test yang disimpan pada suhu dingin $\left(4^{\circ} \mathrm{C}\right)$, suhu ruang $\left( \pm 25^{\circ} \mathrm{C}\right)$ dan suhu tinggi $\left(43^{\circ} \mathrm{C}\right)$. Satu siklus sebanding dengan 24 jam selama 6 siklus.

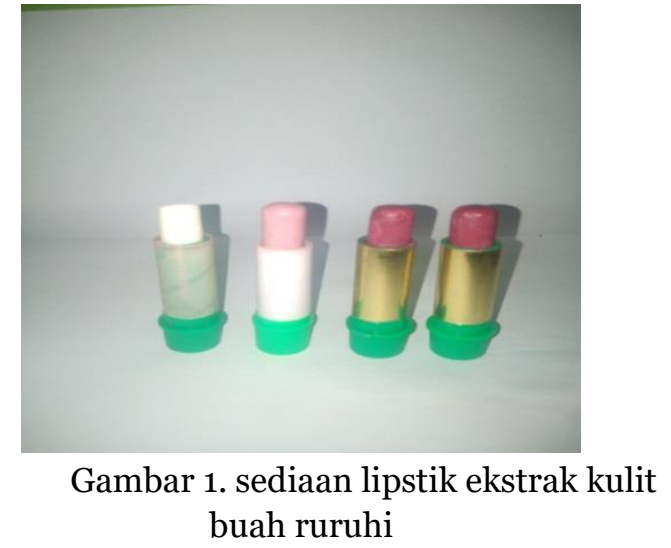

Uji stabilitas

Uji stabilitas sediaan dilakukan dengan melakukan pengamatan terhadap adanya perubahan bentuk, warna, dan bau dari sediaan lipstik dilakukan terhadap masing-masing sediaan selama penyimpanan pada suhu kamar pada setiap mingggu hingga hari ke-30.

Berdasarkan hasil pengamatan keempat formulasi sediaan lipstik menunjukan bahwa seluruh sediaan yang dibuat stabil dalam penyimpanan pada suhu kamar selama 30 hari.Dari hasil pengamatan bentuk, diketahui bahwa seluruh sediaan lipstik yang dibuat memiliki bentuk dan konsistensi yang baik, yaitu bentuk sediaan tetap keras, tidak lembek serta tidak berair maupun berlendir.Bentuknya tetap konsisten selama 30 hari penyimpanan didalam suhu ruang.

Warna sediaan setiap formulasi berbeda-beda dikarenakan setiap sediaan memiliki konsentrasi yang berbeda, yaitu: blanko, 5\%, 10\% dan 15\%. Pada konsentrasi $0 \%$ tidak terdapat warna yang ditimbulkan atau berwarna putih, konsentrasi $5 \%$ warna yang ditimbulkan berwarna merah muda, konsentrasi $10 \%$ berwarna merah, dan konsentrasi 15\% berwarna merah tua. Hasil yang diperoleh bahwa lipstik tidak mengalami perubahan warna, baik warna fisik lipstik maupun warna yang dihasilkan saat lipstik dioleskan. 
Sedangkan bau yang dihasilkan dari seluruh sediaan lipstik adalah bau khas dari pengaroma yang digunakan yaitu oleum rosae.Dalam penyimpanan suhu ruang selama 30 hari oleum rosae pada sediaan lipstik masih tetap stabil dan tidak berubah baunya.

\section{Uji pH}

Uji pH bertujuan untuk mengetahui sediaan pewarna bibir apakah telah sesuai dengan $\mathrm{pH}$ fisiologis kulit bibir. Lipstik yang baik mempunyai nilai keasaman mendekati nilai $\mathrm{pH}$ fisiogis kulit bibir yaitu 3,8 - 4,7 (Siregar dan Utami, 2014)

Pengujian $\mathrm{pH}$ dilakukan setelah sediaan lipstik dibuat dengan konsentrasi yang berbeda-beda. Hasil pemeriksaan pH menunjukan bahwa F1(blanko) tanpa pewarna dari ekstrak kulit buah ruruhi dari minggu ke-1 sampai minggu ke-4 memiliki pH 7, F2 memiliki pH 4, F3 dan F4 memiliki $\mathrm{pH}$ 3. Perbedaan $\mathrm{pH}$ disebabkan oleh perbedaan konsentrasi pewarna dari ekstrak kulit buah ruruhiyang digunakan. Semakin tinggi pewarna dari ekstrak kulit buah ruruhi yang digunakan, maka $\mathrm{pH}$ sediaan lipstik semakin rendah. Hal ini disebabkan oleh pewarna dari ekstrak kulit buah ruruhi memiliki $\mathrm{pH}$ asam.Dalam $\mathrm{pH}$ asam antosianin kebanyakan berwarna merah sedangkan dalam suasana alkali berubah menjadi biru (Mastuti et al,. 2013). Kandungan antosianin didapat dari ekstrak kulit buah ruruhi sehingga sediaan listik dengan kandungan ekstrak kulit buah ruruhi cenderung bersifat asam dan berwarna merah.

\section{Uji Homogenitas.}

Uji homogenitas pada sediaan lipstik dibutuhkan agar diperoleh sediaan lipstik yang homogen.Artinya zat aktif dan zat tambahan lainya dapat menyatu dengan baik. Uji homogenitas sediaan dilakukan dengan cara masing-masing sediaan dari tiap formula lipstik yang dibuat dari ekstrak kulit buah ruruhi berbagai konsentrasi diperiksa dengan cara dioleskan pada kaca yang transparan. Sediaan harus menunjukkan susunan yang homogen dan tidak terlihat adanya butir-butir kasar.

Berdasarkan hasil pengamatan pada tabel 9, sediaan lipstik menunjukkan hasil yang homogen, karena tidak ada pemisahan komponen-komponen dan tidak terlihat adanya butir-butir kasar dalam sediaan.

\section{Uji Iritasi}

Uji iritasi dilakukan untuk mengetahui adakah reaksi yang ditimbulkan pada kulit atau tidak setelah dilakukan pengolesan. Uji iritasi dilakukan dengan 15 orang panelis, masing-masing panelis menggunakan keempat formula sediaan lipstik, yang dilakuan selama 24 jam.

Dari hasil pengujian yang dilakukan panelis memberikan hasil negatif terhadap parameter reaksi iritasi yaitu tidak adanya kulit merah, gatal-gatal atuapun adanya pembengkakan.Dengan demikian dapat disimpulkan bahwa sediaan lipstik aman untuk digunakan.

\section{Uji Kesukaan}

Uji kesukaan dilakukan untuk mengetahui respon atau penerimaan terhadap lipstik yang telah dibuat. Uji kesukaan dilakukan terhadap 15 panelis yang terdiri dari mahasiswa Farmasi Stikes Mandala Waluya Kendari. Pada uji kesukaan panelis masing-masing memilih warna sediaan yang tidak menarik, cukup menarik, sangat menarik. Dari data yang diperoleh untuk formula tidak menarik yakni F1 73,3\%, F2 40\%, F3 20\%, D 6,67\%. Formula cukup menarik F1 13,33\%, F2 33,33\%, F3 40\%, F4 26,67\%, sedangkan untuk formula sangat menarik F1 13,33\%, F2 26,67\%, F3 40\%, F4 $66,67 \%$. 


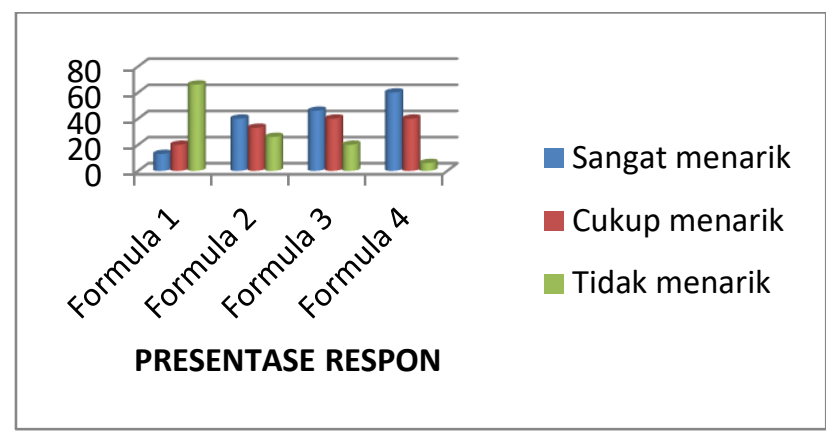

Gambar 2. Diagram uji kesukaan

Sediaan yang sangat menarik adalah formula 4, yaitu dengan konsentrasi pewarna 15\%, untuk sediaan cukup menarik adalah formula 3 dengan konsentrasi pewarna 10\%, sedangkan untuk sediaan tidak menarik adalah formula 1 tanpa ekstrak kulit buah ruruhi.

Hasil serangkaian uji dan evaluasi kestabilan yang dilakukan pada sediaan lipstik ekstrak kulit buah ruruhi, maka dapat disimpulkan bahwa warna sediaan yang paling disukai adalah formula 4 dengan konsentrasi ekstrak $15 \%$ yang memberikan warna merah tua sehingga warna yang dihasilkan sangat menarik dibandingkan dengan formula yang lain.

\section{Uji Cycling Test}

Cycling test merupakan uji yang berguna sebagai simulasi apabila terjadi perubahan setiap tahun bahkan setiap hari. Uji cycling test dilakukan pada suhu dengan interval waktu tertentu sehingga sediaan akan mengalami tekanan yang bervariasi (Maulina, 2011)

Hasil pengamatan setelah uji cycling test menunjukan bahwa keempat formulasi memiliki bentuk yang baik dan konsisten dari awal hingga akhir siklus .Warna sediaan lipstik setiap formulasi berbeda-beda dikarenakan setiap sediaan memiliki konsentrasi yang berbeda, yaitu blanko, 5\%, 10\% dan 15\%.Pada blanko tidak terdapat warna yang ditimbulkan atau berwarna putih, konsentrasi 5\% warna yang ditimbulkan berwarna merah muda, konsentrasi 10\% berwarna merah, dan konsentrasi 15\% berwarna merah tua.
Hasil yang diperoleh warna sediaan tidak berubah tetap memiliki warna yang konsisten dan aromanya pun tidak berubah tetap beraroma parfum oleum rosae yang digunakan.

Hasil pengujian homogenitas sediaan lipstik setelah uji cycling test juga menunjukan bahwa sediaan lipstik pada keempat formula homogen.Hal ini terlihat ketika sediaan lipstik dioleskan pada kaca objek tidak menampakan butir-butir kasar.

Hasil pengujian $\mathrm{pH}$ sediaan lipstik setelah uji cycling test menunjukan bahwa nilai pH pada F1 (blanko) dan F2 (5\%) tidak terjadi perubahan sedangkan pada F3 (10\%) dan F4 (15\%) terjadi peningkatan $\mathrm{pH}$ pada minggu ke-3 hingga minggu ke-4. Sediaan dikatakan tidak stabil karena terjadi perubahan adanya peningkatan $\mathrm{pH}$, tetapi perubahan tersebut tidak terlalu signifikan karena masih termasuk dalam rentang $\mathrm{pH}$ fisiologis bibir yaitu 3,8 - 4,7.

\section{KESIMPULAN}

Berdasarkan dari hasil penelitian yang dilakukan mengenai formulasi sediaan lipstik ekstrak kulit buah ruruhi dapat diperoleh kesimpulan sebagai berikut :

1. Ekstrak kulit buah ruruhi dapat digunakan sebagai bahan pewarna alami dalam formulasi sediaan lipstik dengan memberikan warna yang baik pada konsentrasi ekstrak 10\% dan $15 \%$.

2. Sediaan lipstik dengan zat warna dari ekstrak kulit buah ruruhi stabil secara fisik pada kondisi penyimpanan suhu ruang $25^{\circ} \mathrm{C}$ tetapi tidak stabil pada kondisi cycling test $\left(4^{\circ} \mathrm{C}\right.$ dan $\left.43^{\circ} \mathrm{C}\right)$.

\section{UCAPAN TERIMA KASIH}

Penulis mengucapkan terima kasih kepada semua pihak yang telah berkontribusi dalam penelitian ini, 
sehingga peneliian dapat terlaksana dengan baik.

\section{DAFTAR PUSTAKA}

Adliani, Nur.,Nazliniwaty., Danpurba, Djandakita. 2012. Formulasi Lipstik Menggunakan Zat Warna Dari Ekstrak Bunga Kecombrang (Etlingeraelatior (Jack) R.M.Sm), Journal Of Pharmaceutics And Pharmacology. 2 : 87-94.

Agoes, G. 2015. Sediaan kosmetik (Sfi9).Bandung:ITB press

Asfy nurany., Andisri Suriatiamal., Solika hanaestikomah. 2018. Formulasi Sediaan lipstik ekstrak bunga rosella (Hibiscus sabdariffa) Sebagai pewarna dan minyak Zaitun (Olive oil) Sebagai emolien. Jurusan farmasi unida gontor.Jawa Timur

Depkes, Permenkes RI, No. 1175/Menkes/Per/VIII/2010, Tentang Pewarna Bibir (Lipstik). Jakarta; Depkes RI. 2010

Ditjen POM. 1985. Formularium

Kosmetika Indonesia. Jakarta:

Departemen Kesehatan

Republik Indonesia. Hal. 22,235

Dirjen pom departemen kesehatan republic indonesia. 1979. Farmakope Indonesia,Edisi III. Jakarta: Departemen kesehatan republicindonesia

Dirjen pom departemen kesehatan republic indonesia. 1995. Farmakope indonesia Edisi $I V$. Jakarta: Departemen kesehatan republic indonesia

Heyne,K. 1987. Tumbuhan berguna Indonesia Jilid 3,1522.Saranawana : Jakarta.

Irnawati.,Wa Ode Sitti zubaydah.,Arifah. 2017. Anthoycanin Total And Antioxidant Activity of Ruruhi (Syzygium polycephalum merr) Fruits.Jurusan farmasi fakultas farmasi halu Oleo University :Kendari

Kibbe, A. H., 2000, Handbook Of Pharmaceutical Excipients, Third
Edition, Pharmaceutical Press London, United Kingdom and American Pharmaceutical Association, Washington, D.C

K.P, Octaviani. 2014. Pengaruh Basis Beeswax Dan Paraffin Wax Terhadap sifat Dan Stabilitas fisik sediaan lipstick ekstrak etanolik bunga kembang Sepatu (Hibiscus Rosa-Sinensis L.) Beserta uji iritasi primernya. Yogyakarta :Skripsi. Universitas gadjah mada

Lestiana, Chyntia. 2014, Formulasi lipstick ekstrak etanolik mahkota bunga kembang Sepatu (Hibiscus Rusasinensis L) Beserta uji iritasi primernya. Journal

Of Pharmaceutics Pharmacolog.Hal : 6

Maulina, Ikadwi. 2011. Uji stabilitas fisik dan aktivitas antioksi dan sediaan krim Yang Mengandung ekstrak umbi (L.): Depok

Nurhasnawati, H., Sukarmi dan Fitri H., 2017, Perbandingan Metode Ekstraksi Maserasi dan Sokletasi Terhadap Aktivitas Antioksidan Ekstrak Etanol Daun Jambu Bol (Syzygium malaccense L.), Jurnal Ilmiah ManuntungVol.3 No.1 : 3

Raymond C Rowe, Dkk. 2006. Handbook of Pharmaceutical Excipients Sixth Edition. Washington.

Raymond C Rowe, Dkk. 2009. Handbook Of Pharmaceutical Excipients Sixth Edition. Washington.

Risnawati, Naziniwaty., Danpurba, Djendakita. 2012, Formulasi lipstick menggunakan ekstrak biji coklat (Theobroma Cacao L) Sebagai pewarna. Journal Of Pharmaceutics And Pharmacology. $1: 78-86$.

Pracima, Rosita. 2015, Pemanfaatan Ekstrak Ubi Jalar Ungu (Ipomea batatas (L.) Poir) Sebagai Zat Warna Pada Sediaan Lipstik. Jakarta: Skripsi. Universitas Islam Negeri Syarif Hidayatullah

Satheesh, M dan abhay,P.Y.2011.Lip: Animpressive Andidealisticplat form For drug delivery.Journal 
Of pharmacy research. 4(4). Hal. 1

Tiwari, Kumar, Kaurmandeep, Kaurgupreet \& Kaur Harlem. 2011. Phtochemical Screening And Extraction : A Review Intenationale Pharmaceutical Science Vol.1
Tranggono RI dan Latifah F, 2007. Buku Pegangan Ilmu Pengetahuan Kosmetik, PT Gramedia Pustaka Utama, Jakarta : Hal. 11, 90-93, 167 Verheij, E.W.M, Dan R.E Coronel. 1997. Sumber daya nabati Asia Tenggara 2: Buah-Buahan Yang Dapat dimakan. Gramedia : Jakarta . Isbn 979-511-672-2 